\title{
JetBlue Airways: Service Quality As A Competitive Advantage
}

\author{
Bill Dodds, (E-mail: dodds_b@fortlewis.edu), Fort Lewis College
}

\begin{abstract}
JetBlue's exemplary business model is a solid teaching case covering the conceptual literature of the price-quality and satisfaction link, service profit chain as well as service quality -profit model.
\end{abstract}

\section{THE DYSFUNCTIONAL AIRLINE INDUSTRY}

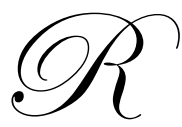

ight now the U.S. airline industry is in an economic tailspin. Few industries have such awful labormanagement relations and dysfunctional cultures as in the airlines. Stanford Business School Professor Jeffrey Pfeffer agrees, noting in a 1994 article:

In the United States, with few exceptions, most airlines have followed practices with respect to their employees that are, for the most part, diametrically opposite of what would be required to achieve competitive advantage through people -- and this in a service industry.

While low-cost carriers like Southwest, JetBlue, and AirTran continue to thrive, the majors, whose origins date back to the fat and happy (and expensive) era before deregulation in 1978, are reeling. And so what do the major carriers do in response to the inroads that the discount airlines made? Do they say 'we need to urgently respond to this new high service/low cost marketplace paradigm'? No! Instead they say 'we're going to cut back on our service even more. We're going to operate fewer flights and longer connections. We're going to increase our fares, and we'll make flying with us even more miserable than it already is.'

It is no wonder that the abused traveling public - but blessed with a ton more sense than a roomful of airline executives - did the obvious thing. They cut back on their flying. They refused to pay ridiculous fares with no associated benefits. They switched to decent airlines with decent fares and decent service.

\section{JETBLUE'S APPROACH TO CUSTOMER SATISFACTION}

Jet Blue truly is an amazing airline, which treats all of it's customers as equals, regardless of their status. The flights are probably the most comfortable of all of the airlines with leather seats, more leg room than most passengers are accustomed to on other airlines, great in-flight entertainment, and with people who are the most helpful in the industry. Jet Blue is one of the few airlines that offer free Direct TV as well as XM satellite radio providing passengers with 100 channels of largely commercial free programming, from all sorts of different styles of music, and talk. From the company's inception, JetBlue's founders were aware that its seemingly contradictory goals-the internal mantra is "high touch, low cost"-were achievable only through aggressive and strategic use of technology. They are aggressive where it makes sense-that's why they have DirecTV in every seat, and why they're ahead of the pack on Web services. At the same time, they standardize where it makes sense, from their PCs right up to the airplanes. As JetBlue continues to conquer the odds, their repeated choice of Airbus aircraft proves that efficiency on all levels, including equipment and operations, is a must for an airline's continuing health. JetBlue demonstrates that with the right people, the right product and the right cost structure, airlines can grow, even in this current, challenging, environment." 
On top of this, they have the cheapest flights around, flying all over the country, at rates that other airlines wouldn't even give their own employees. Besides being comfortable and cheap, they're preassigned, unlike Southwest Airlines. Roundtrip from JFK to Florida can cost as little as \$138, with no Saturday night stay required and just a seven-day advance purchase. And there aren't any rubber chicken entrees onboard, just all-you-can-eat supplies of Terra Blue potato chips, Animal Crackers, and other fun snacks that don't cost much.

\section{Jetblue's Connection To Service Quality Through Productivity}

Productive people. JetBlue is extremely picky when it comes to selecting employees to work for them. They made finding employees who know how to retain customers such a priority that getting hired is harder than being accepted into the Ivy League. Last year 130,000 applicants vied for 2,000 jobs. To choose its hires, JetBlue tests them on how they would handle a long list of hypothetical situations involving demanding passengers.

JetBlue attracts and motivates talented crewmembers in a number of ways, including developing a welldeserved reputation for treating crewmembers well and having a great work environment, offering the opportunity for rapid advancement, scheduling efficiently, and contributing $15 \%$ of profits to a crewmember profit sharing plan. Key motivators also include stock options and especially the generous employee stock purchase plan -- both of which are linked to JetBlue's soaring share price.

In summary, JetBlue achieves tremendous labor productivity in a number of ways:

1. Employees feel valued and respected and have a sense of ownership, which translates into a motivated, productive workforce.

2. JetBlue flies one type of aircraft, which keeps training costs down, improves productivity, and increases scheduling flexibility.

3. Flight Attendants pursue an aggressive trash-collection policy, which allows JetBlue to turn planes around in about 35 minutes--compared with the hour or more at other airlines--giving JetBlue the opportunity to sell more flights per day.

4. On average, its pilots are paid for 83 hours per month, of which $82 \%$ are "block hours" -- the time from when a plane pushes back from one gate and arrives at another. This is a critical measure of pilot productivity since an airline only earns money during block time. JetBlue maximizes this metric primarily by reducing training time (again, flying one type of plane) and by shunning the industry-standard hub-andspoke system and its associated delays between flights.

Productive Planes. Given an airplane's high cost, it's critical to squeeze every ounce of productivity from them. To keep aircraft operating costs low, JetBlue buys only new planes, which tend to need less maintenance and, even better, come with a five-year warranty. But equally important, JetBlue keeps its planes in the air -- the only time when they're earning revenues -- an average of 13 hours per day. This is the highest in the industry, $18 \%$ higher than Southwest (11 hours, though again this is largely due to JetBlue's longer flights) and 44\% more than Delta (9 hours).

JetBlue achieves this productivity because:

1. Its planes are at the gate for, on average, 35 minutes, vs. an hour or more for most airlines.

2. New aircraft tend to spend less time out of commission due to unexpected breakdowns and scheduled maintenance.

3. With many coast-to-coast routes, JetBlue flies many planes on all-night "red-eye" flights to reposition them for the next day schedule.

4. $\quad$ As JetBlue grows, one of its technology tools is an "operational recovery system." During any disruption -weather that grounds some flights, for example -- it allows planners to select various goals before rerouting planes while meeting criteria such as no canceled flights or delays beyond three hours. The software produces a solution and calculates its cost. It factors in each plane's maintenance and fuel needs, and the flight crew's experience and availability within FAA rules. 


\section{Jetblue's Service Quality And Satisfaction Model}

How customers perceive services, how they assess the experienced service quality, and whether they are satisfied is at the center of the turmoil in the airline industry. The entire issue of service quality and satisfaction is based upon customers' perceptions of the service, not some preconceived management notion of what service is or should be.

These customer-oriented terms, service and product quality and satisfaction have been the focus of attention for airline executives. It is just a matter that airlines like Southwest and JetBlue have a deeper understanding of its impact upon profitability.

In figure 1, service quality is a focused evaluation that reflects the customer's perception of the element of service such as:

1. interaction quality which involves the service personnel of the airlines,

2. physical environment quality which includes the terminal and the planes, and

3. $\quad$ outcome quality which includes the experience of getting from point A to point B.

Each of these elements are evaluated upon the basis of the following elements of service quality

1. Reliability: Perform promised service dependably and accurately, i.e. the planes leaves and arrives on time

2. Responsiveness: Willingness to help customers promptly, i.e. flight leave at times when passenger desire to travel

3. Assurance: Ability to convey trust and confidence, i.e. flight attendants that cater to the needs of passengers in a warm and courteous manner.

4. Empathy: Ability to be approachable, i.e. passengers knowing that their complaints are being heard and acted upon.

5. Tangibles: Physical facilities and facilitating goods, i.e. the planes are new, clean and with comfortable seats.

Figure 1: The Price - Service Quality and Satisfaction Link

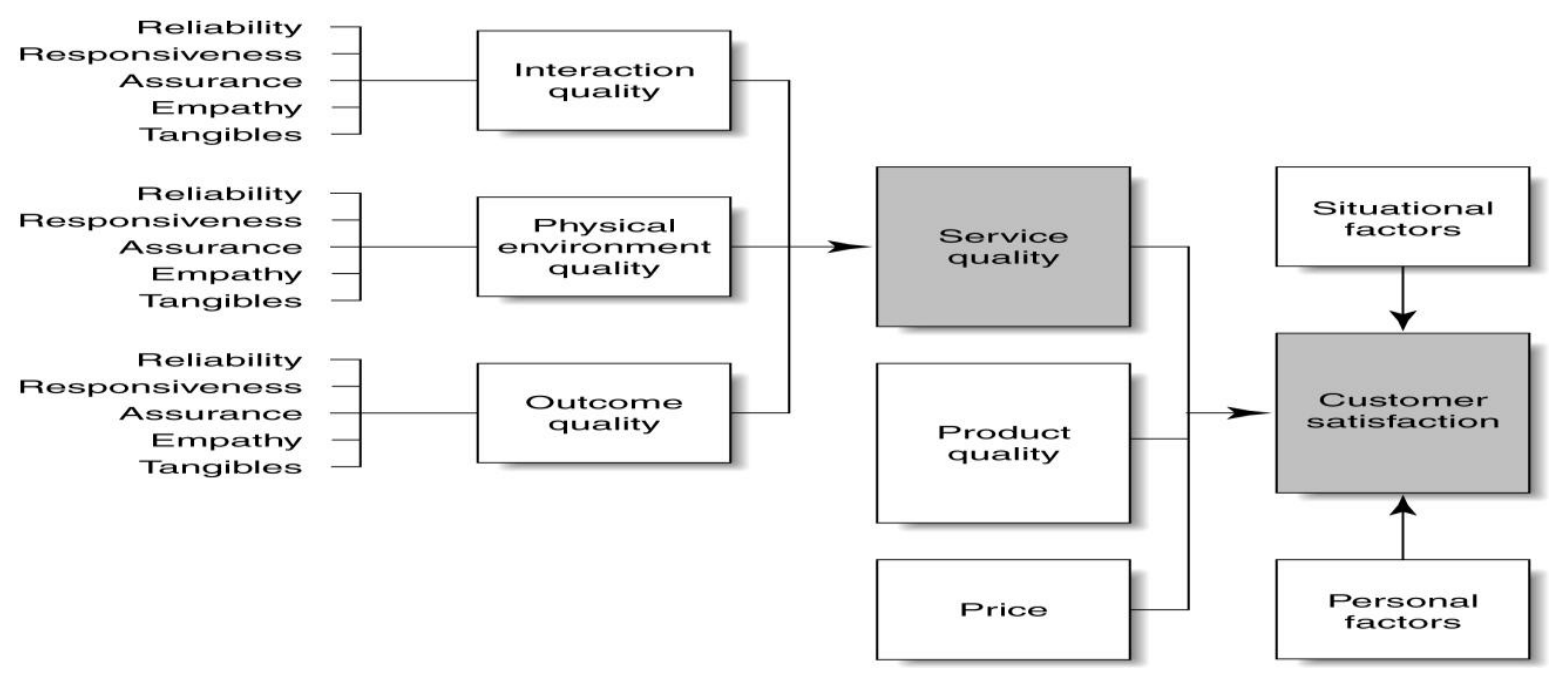

Source: Zeithaml and Bitner's Services Marketing 2003 
Customer satisfaction is a broader concept that is determined by the passenger's perception of service quality as well as the perception of product quality, price, personal and situational factors. The outcome on customer satisfaction is dependent on the ability of the overall airline experience to meet or exceed the expectations of the passenger.

Consistently delivering an exceptionally positive customer experience is the key to long-term business success in any industry. Doing so, however, is extremely complex and difficult. Yet once achieved, it can feed on itself, creating a virtuous cycle and becoming a powerful competitive advantage -- one that can be very difficult for competitors to match. JetBlue clearly understands this and the results show. So far, JetBlue is achieving their service quality goals. Consider the following table for the full year 2005:

Table 1

2005 Airline Quality Rating

\begin{tabular}{lcccc}
\hline \multicolumn{1}{c}{ Rank } & On-time & Mishandled bags ${ }^{1}$ & Denied boardings & Complaints $^{3}$ \\
1. JetBlue & $81.8 \%$ & 2.99 & 0.01 & 0.27 \\
2. AirTran Airways & $77.7 \%$ & 2.82 & 0.28 & 0.89 \\
3. Southwest & $80.1 \%$ & 3.35 & 0.95 & 0.18 \\
4. United & $79.7 \%$ & 3.93 & 0.49 & 0.89 \\
5. Alaska & $76.5 \%$ & 3.51 & 1.22 & 0.58 \\
6. America West & $75.7 \%$ & 3.98 & 0.70 & 1.02 \\
7. Northwest & $79.1 \%$ & 4.22 & 0.78 & 0.89 \\
8. American & $76.8 \%$ & 4.73 & 0.52 & 0.88 \\
9. Continental & $78.9 \%$ & 3.58 & 1.76 & 0.82 \\
10. American Trans Air & $79.8 \%$ & 3.82 & 2.33 & 0.79 \\
1 - per 1,000 passengers & & & \\
2 - per 10,000 passengers & & & \\
3 - per 100,000 passengers & & & \\
Source: 2005 Airline Quality Rating, based on Department of Transportation figures & & \\
\hline
\end{tabular}

Findings from the 2006 study by J.D. Power Associates and Aviation Week magazine are based on responses from 9,334 passengers, who flew on a major North American airline this year between January and May.

Overall customer satisfaction with both low-cost and traditional, multi-cabin carriers was measured by seven factors, in order of importance: cost and fees; quality of flight crew, including courtesy and appearance; inflight services, such as the availability of food and beverages; ease of check-in; timeliness of boarding, deplaning and baggage retrieval; aircraft features, such as adequate leg room; and quality of flight reservation services.

The study finds that 'process' factors, such as check-in, how passengers board the plane and how baggage is delivered at the destination; and 'people' factors, such as hiring the right people and training and enabling them to be successful, are what differentiate carriers in the eyes of passengers.

"JetBlue is true to its business model, in which it promises its passengers a comfortable seat with a television monitor, peanuts and service with a smile," said Linda Hirneise, executive director for travel at J.D. Power and Associates, in a written statement on the 2006 Airline Satisfaction Index Study, "They've never offered services such as in-flight meals, but they make up for it with amenities passengers truly value and with their service," 
Hirneise said. They clearly understand the implication of customer satisfaction issues that ultimately leads to profitability. These issues are clearly points of competitive advantage that underlies their success story.

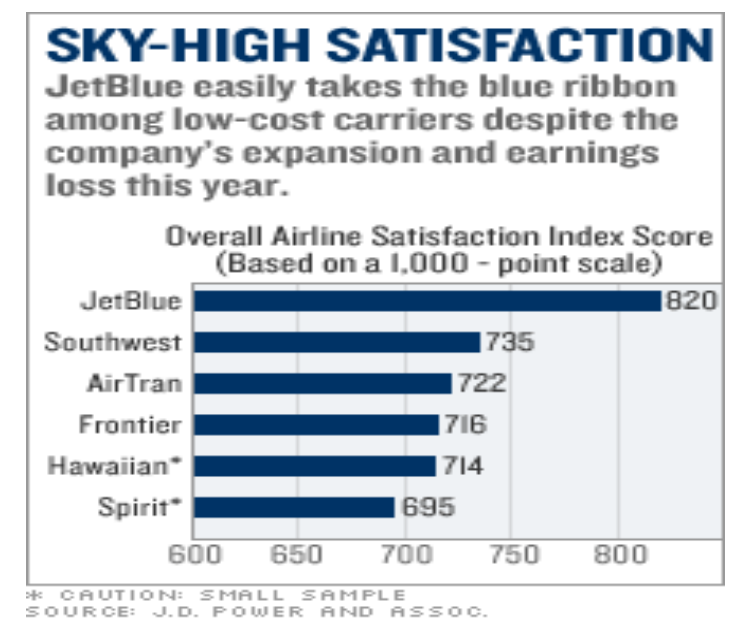

\section{JETBLUE'S SERVICE PROFIT MODEL}

The importance of a strong culture in a tremendously labor- and service-intensive industry like the airlines cannot be stressed enough. In the words of one long-time United Airlines pilot:

You can focus on cost per seat mile (CASM), revenue per seat mile (RASM), yield, stage length, turns, you name it. The real reason things are going well at JetBlue, at least looking at it from the other side of the fence, is the human relations and values of management. Why are Southwest and JetBlue profitable, when much of the rest of the industry is unprofitable? There are many factors, but among the most overlooked are their motivated, passionate workforces. By focusing energy on their employees, Southwest and JetBlue may have found the secret ingredient to airline success.

The service profit chain (see figure 2) illustrates a relationship that links employee output quality and productivity to service value to customer satisfaction to loyalty resulting in revenue growth and profitability. JetBlue has adeptly structured their marketing, operations and human resources to leverage revenue enhancement and profitability through the service profit chain. While each functional area has specific responsibilities, David Neeleman, Chairman and CEO, and his managing team were specific about coordination that would ensure JetBlue could deliver superior quality at a lower price. JetBlue certainly perfected the application of the service profit chain. Here is what they did. 
Figure 2:The Service Profit Chain

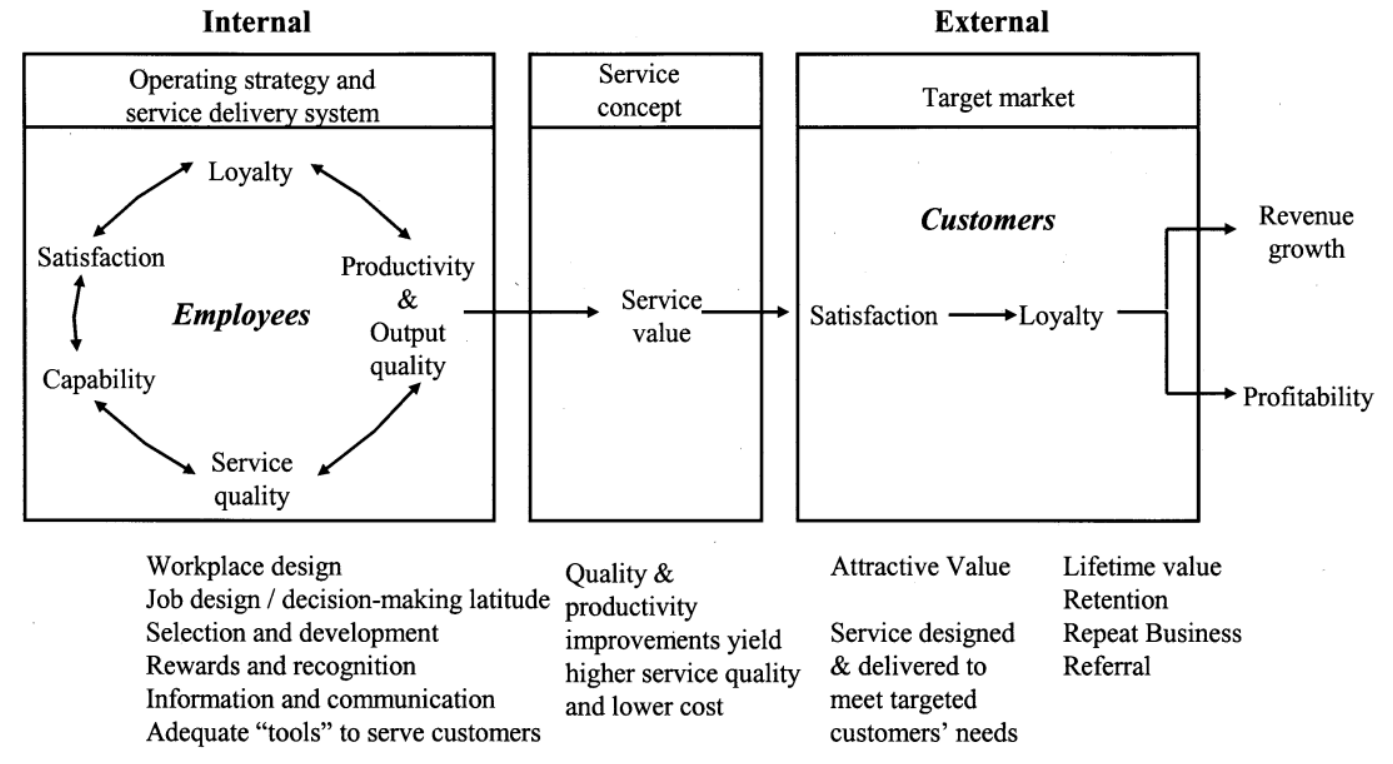

Source: "Putting the Service Profit Chain to Work," by James L Heskett, Thomas O. Jones, Gary W. Loveman, W. Earl Sasser Jr, and Leonard A. Schlesinger, Harvard Business review (March-April 1994: 166

\section{The Internal Environment}

JetBlue's investment in their employees through the six activities such as workplace design fosters the operating strategy and service delivery system. JetBlue's satisfied, committed, capable and productive employees created a quality service at a reduced cost. The combined nature of productivity and quality is what drives service value.

A JetBlue flight attendant who used to work for United relates anecdotal evidence that while her base pay is lower; she makes it up by working overtime and participating in the stock purchase plan.

I like working for JetBlue because the company treats me well, I am already quite senior (meaning that I have my pick of routes), and my fellow flight attendants work as hard as I do. At United, relations with management were terrible, I was among the most junior flight attendants (which was why I was laid off), and was often frustrated by burnt-out, unmotivated colleagues who -- knowing that our union would protect us -- were rude to passengers or simply sat at the back of the plane during the bulk of the flight. The attitude at JetBlue is very evident when you walk up to the counters and are greeted by someone that actually seems to want to help you out. The service attendants are always willing to go above and beyond to make sure that you have a great flight and to make sure that you find everything that you need.

\section{Service Value}

Jetblue's service value is deeply embedded in its highly productive people and highly productive aircraft. When coupled with the output quality motivated by the caring culture of the organization, this combines to produce a high service value. Passengers look for value when they fly. That means they're looking for a quality service at a fair price. But how do they determine those elusive "qualities" of value? For JetBlue this comes easy because they do the things that their competitor can't or won't do 


\section{The External Environment}

"JetBlue is the way flying should be, and probably the way it was some time ago," says Albert James, a New York City-based application architect who flies to Florida at least twice a year on the carrier. "The agents at check-in are efficient. In flight, you get first-class service no matter where you sit. Even baggage claim is a breeze. I have yet to have a bad JetBlue experience."

After airline passenger taste the JetBlue experience, it comes very hard for them to return to the so called major airlines where the perception is "less for more." Hence, JetBlue has been able to quickly gain a satisfied and loyal set of flyers. While this leads to repeat business, it also provides free word of mouth advertising to attract additional customers. In its short life, JetBlue has been able to show gains in revenue as well as profitability. Companies, such as JetBlue understand the leverage of increasing customer loyalty by a small percentage can dramatically increase profits. A 5\% increase in loyalty could increase profits from $25 \%$ to $85 \%$, depending on cost structure.

Clearly, the implementation of the service profit chain requires a thorough understanding of how marketing, operations and human resources each relate to a company's broader strategic concerns.

\section{Service And Profitability ${ }^{1}$}

Anyone who has ever experienced Jet Blue's planes, cabin crew, and ground staff will tell you for as long as you care to listen how amazing this carrier is. Better planes, better seats, better service, better fares - better everything. You'd be nuts to fly any other carrier if Jet Blue has a comparable schedule and fare. David Neeleman and his team clearly understood this experience and have continued to build on the notion that better service would lead to improved financial success. Service quality helps JetBlue to attract more and better customers to an airline through offensive and defensive marketing (see figure 3).

Figure 3:

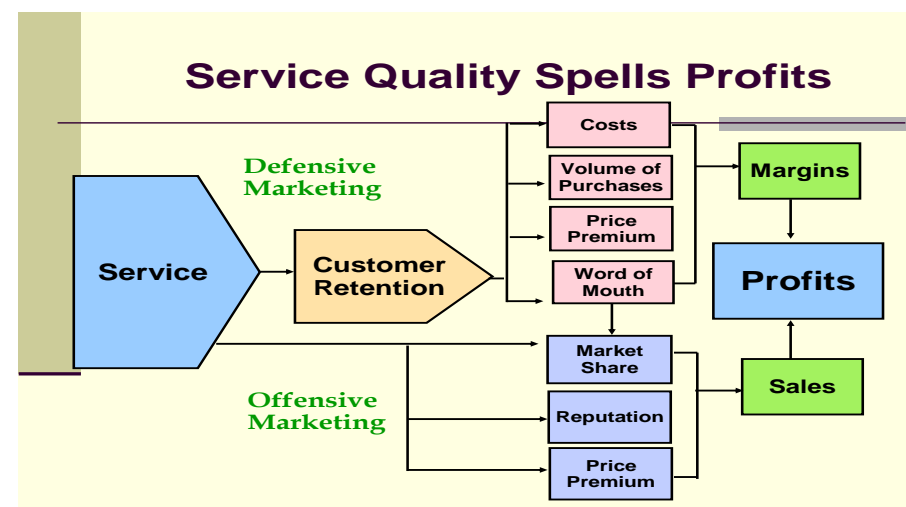

Source: Valarie A. Zeithaml and Mary Jo Bitner's Services Marketing: Integrating Customer Focus Across the Firm, $3^{\text {rd }}$ edition, 2003

\footnotetext{
${ }^{1}$ In spite of JetBlues commitment to service quality, environmental issues such as increased fuel prices has contributed to consecutive losses in the $4^{\text {th }}$ quarter of 2005 and the $1^{\text {st }}$ quarter of 2006 "We are disappointed to report our second consecutive quarterly loss," said David Neeleman, JetBlue's Chairman and CEO. "As we face what might be the 'new normal' for fuel prices, we have developed a comprehensive 'Return to Profitability' plan. As part of the Return to Profitability Plan, JetBlue's leadership team completed an extensive evaluation, which identified opportunities to decrease costs, increase labor efficiencies and improve revenue performance, while keeping the JetBlue Experience unique and continuing to meet customer expectations. Specific initiatives of this plan will be rolled out throughout 2006 and include a variety of revenue enhancement initiatives, more efficient fuel usage and conservation efforts, more rigorous supply chain management and a broad review of all expenses throughout the organization.
} 


\section{Offensive Marketing}

This strategy is all about gaining new customers in order to build revenue through higher market share, stronger reputation and higher prices, In general, a company which gains a positive reputation places itself in a position to build higher market share and the "privilege" to charge more than its competitors for services. In JetBlue's case, they declined the opportunity to charge a premium price but rather pursued a low price strategy to further increase market share and create the mystique of superior quality at lower prices. The combination of low prices and high quality has created a substantial competitive advantage for their competitors to overcome. To add insult to injury for the so called major airlines, JetBlue's pricing policies are very attractive to the business traveler, once the bread and butter for the competing majors.

\section{Defensive Marketing}

This strategy is targeted at increasing profit margins through customer retention. When it comes to keeping passengers, JetBlue executes a devastating defensive marketing strategy. "Customer churn can be costly for JetBlue, so to minimize this turnover, the JetBlue value proposition of better quality for less money keeps their passengers from flying on competing airlines. Getting new customers is expensive; it involves advertising, promotion, and sales costs as well as startup operating expenses. New customers are often unprofitable for a period of time after acquisition, but through retention, JetBlue can enhance their profit margin by reducing their costs, increasing their volume, and benefiting from free word-of-mouth advertising. While they are justified in charging a premium price, they prefer to keep prices low to intensify their value proposition.

\section{Summary of the JetBlue Strategy}

David Neeleman and his management team made great strides toward achieving "the very simple goal of bringing humanity back to air travel." Neeleman said Humanity! Notice he didn't say, "Bringing low fares and good service back to air travel." He said, in effect, that most airlines treat their customers in an inhumane fashion and that he was determined that JetBlue would be "a different kind of airline." This thinking internalized into a strategy has made all the difference for JetBlue.

The case was prepared by Professor Bill Dodds, School of Business Administration, Fort Lewis College. It is intended as a basis for classroom discussion and analysis and to reflect some of the issues faced in the airline industry. The case is not designed to illustrate effective or ineffective handling of an administrative situation. The case is based on the following sources:

\section{REFERENCES}

1. Whitney Tilson (2003), JetBlue's Beautiful Cost Structure, TheMotleyFoolcom, July 11.

2. Whitney Tilson (2003), JetBlue's Customer Experience, TheMotleyFoolcom, July 25.

3. Whitney Tilson (2003), JetBlue's Friendly Skies, TheMotleyFoolcom, August 8.

4. Whitney Tilson (2003), JetBlue's Challenges, TheMotleyFoolcom, September 19.

5. U.S. Department of Transportation (2004), BTS Releases Third Quarter 2004 Airline Financial Data (http://www.dot.gov/affairs/bts3504.htm).

6. Todd Burke (2005), JetBlue Announces First Quarter 2005 Earnings, PrimeZone Media (JetBlue press release), April 21.

7. Stephaine Overby (2002), JetBlue Skies Ahead, CIO Magazine, July,1.

8. What is the deal with all the Jet Blue insanity, Epinions, January 8, 2005 (http://www.epinions.com/content 168882441860).

9. Arlyn Tobias Gajilan 2003), The Amazing JetBlue, Fortune Small Business, May.

10. JetBlue Announces First Quarter 2005 Earnings, PrimeZone Media, April 21, 2005

11. James L Heskett, Thomas O. Jones, Gary W. Loveman, W. Earl Sasser Jr, and Leonard A. Schlesinger Putting the Service Profit Chain to Work, Harvard Business review (March-April 1994: 166.

12. Valerie Zeithaml and Mary Jo Bitner Services Marketing 2003. 


\title{
TEACHING NOTE
}

\author{
Jetblue Airways: A Case Study In Service Quality As A Competitive Advantage
}

Synopsis

JetBlue's exemplary business model is a solid teaching case covering the conceptual literature of the price-quality and satisfaction link, service profit chain as well as service quality - profit model. Jet Blue truly is an amazing airline, which treats all of it's customers as equals, regardless of their status. The flights are probably the most comfortable of all of the airlines with leather seats, more leg room than most passengers are accustomed to on other airlines, great in-flight entertainment, and with people who are the most helpful in the industry. JetBlues accomplishes this in the context of an industry mentality where most airlines have followed practices with respect to their employees that are, for the most part, diametrically opposite of what would be required to achieve competitive advantage through people - and this in a service industry. Few industries have such awful labor-management relations and dysfunctional cultures as in the airlines.

The case provides a real example of how service quality links to customer satisfaction and when combined with the productivity and output quality of JetBlue's employees leads to profitability in a very difficult industry.

\section{Teaching Objectives}

Since most students have had experiences flying on commercial airline and probably will have some "horror" stories to tell, the JetBlue Airways: Service Quality as a Competitive Advantage case offers a refreshing examination of how sound services marketing principle, applied in a well planned and implemented manner leads to success in an industry that is dogged by poor service practices. The following objectives should be reinforced in the teaching of this case:

1. To understand that service quality, as it applies to the commercial airline industry, is a focused evaluation that reflects the customer's perception of the elements of service such as:

interaction quality which involves the service personnel of the airlines, physical environment quality which includes the terminal and the planes, and outcome quality which includes the experience of getting from point A to point B.

2. To recognize that customer satisfaction is a broader concept, determined by the passenger's perception of service quality as well as the perception of product quality, price, personal and situational factors. The outcome on customer satisfaction is dependent on the ability of the overall airline experience to meet or exceed the expectations of the passenger.

3. To comprehend the complex and difficult task of consistently delivering an exceptionally positive customer experience, but once achieved, this culture of customer experience can feed on itself, creating a virtuous cycle and becoming a powerful competitive advantage.

5. To appreciate the linkages that exist in the service profit chain that unites the productivity and output quality of employees to provide service value that will then lead to satisfaction and loyalty from the passengers of JetBlue. This linkage leads to increased revenues, reduced costs and thus increased profitability.

6. To comprehend that competitive advantage can be continuously eroded by competitive action and therefore a firm like JetBlue needs to engage in offensive and defensive strategies to maintain the advantages they have leveraged.

\section{Teaching Suggestions}

This case can be used for in class discussion, outside project work as well as a suitable examination case. The case can be used in the teaching of services marketing and there would fit well into principles of marketing, 
marketing strategy as well as a services marketing course. The section below provides many suggestions for effective exploration of the issues brought forward in this case.

The concept of internal marketing is often ignored in the teaching of marketing where the focus is often on customers and the marketing mix. Herb Kelleher, former CEO of Southwest Airlines and Danny Meyer, a distinguished New York City restaurateur view marketing quite differently . It is not coincidental that both Kelleher and Meyer espouse the philosophy that that the customer "comes second" and the employees "come first." Links to excellent article by these visionary business leaders are provided.

Kelleher, A Culture of Commitment http://leadertoleader.org/leaderbooks/121/spring97/kelleher.html Meyer, The Business of Hospitality http://www.time.com/magazine/article/0,9171,00.html

Internal marketing means turning the focus of selling from your customers to your employees. Employees need to be aware and be willing to provide support that will ensure the success of your service organization. The employees of a service organization such as JetBlue represent the "face" of the organization. They meet, greet and serve customers in a variety of different ways, face-to-face, on-line, via telephone and so on. Customer relationships depend on their attitude and their loyalty. In turn they build loyalty longer term for the company. The longevity of customer relationships is a continuing issue for many companies as it costs more to recruit a new customer than often to serve a customer of longer standing.

Just consider what happens if the internal and external faces of a service are not coordinated.

1. Bad ground and in-flight service can totally alter your perception of a "customer friendly" airline. The delivery does not live up to the brand offer.

2. An international hotel where the reception staff clearly has not seen the hotel advertising. They are supposed to help their guests.

3. Outsourced catering facilities in leisure attractions are sometimes unable to carry the same values as the theme park. At a minimum, they should be synergistic.

4. A grumpy waiter in a fast food outlet can totally destroy welcoming family brand values.

5. Conversely, Nordstrom staff enhance the brand offer by being empowered to serve the client. They select staff who fit their culture, those who have likeable personalities.

6. Dell customer care through call centers surrounds the brand with a service halo.

7. First Direct can treat all of its customers the same way because they understand their customers' financial requirements.

Marketing attention is becoming more introspective within the company because the synchronization of the external and internal positioning of the service is vital.

Areas for Discussion/Analysis

1 Evaluate the claim that JetBlue's success is rooted in its claim of productive people and productive plans. Why do other airlines have trouble emulating this approach?

2 What role does technology play in the development of outstanding service equality?

3 Other than the factors of being on time, mishandled bags, denied boarding and complaints, what would be a more comprehensive list of indicators leading to passenger satisfaction? As a class activity, assign relative weights to these factors as well as the four factors used by the US Department of Transportation to develop a more complete evaluation of airline service. [Hint: It would be a great exercise to develop a flowchart of service encounters for a passenger that decides to make an airplane trip from Denver to Boston. Start at the first contact with the airline to last contact prior to leaving the terminal at the destination.]

4 Using Figure 1 in the case (The Price-Service Quality, and Satisfaction Link) and the service encounter diagram developed in question 3 above, analyze each satisfaction factor and sort into interaction quality, physical environment quality and outcome quality groups and then attach the most appropriate service 
quality attribute (reliability, responsiveness, assurance, empathy and tangibles) to each service encounter attribute.

5 Who comes first? The customer or the employee? Use the Service Profit Chain Model as a basis for discussion. Is this just another "chicken or the egg" question. How has the management of JetBlue approached this question?

6 Consider the following statements in regard to Figure 2: Service Profit Chain. How has JetBlue leveraged these relationships?

Internal quality drives employee satisfaction.

Employee satisfaction drives retention and productivity.

Employee retention and productivity drives service value.

Service value drives customer satisfaction

Customer satisfaction drives customer loyalty.

Customer loyalty drives profitability and growth.

7 If you were in charge of JetBlue, how would you use Figure 3: Service Quality-Profit Relationship to continue your success in attracting new passengers as well as retaining existing passengers? Be specific about costs, volume, price premium, word of mouth for your defensive strategy as well as market share, reputation, and price premium for your offensive strategies.

\section{SUMMARY}

JetBlue Airways is an exemplary company that has learned from the best such as Southwest Airways and from its inception embedded technology into its organization structure and along with productive people and planes has bridged the seemingly contradictory goals of high touch, and low cost through aggressive and strategic use of technology as well as sound service quality principles..

\section{NOTES}


NOTES 